\title{
Partial failure diagnostics system in complex agricultural machinery
}

\author{
Alexei Zotov ${ }^{1}$ and Vadim Gritsenko, ${ }^{1, *}$ \\ ${ }^{1}$ Don State Technical University, Gagarina sq., 1, 344003 Rostov-on-Don, Russia
}

\begin{abstract}
The authors presented a work that raises the reliability of agricultural machinery, the organization of diagnostic procedures and the effective use of units by reducing downtime. It is proposed to organize the diagnostic process according to the hierarchical principle and use the expert system to analyze the state of the object in the current situation. The diagram of the structure of the diagnostic system using the center of the state analysis is presented. The article is of interest to specialists working in the field of operating grain harvesters and increasing the productivity of agricultural work.
\end{abstract}

\section{Introduction}

Diagnostic procedures in technical devices are designed to solve problems about the place, type and causes of failures. The first tasks are solved with the help of models developed during the design process, special tests or by processing control information on the spot. The latter task requires an integrated approach, taking into account both operational information about the impacts on the failed object, and some background associated with the life cycle of this object from the manufacturer to the moment of failure.

It is no longer possible to solve the entire complex of diagnostic tasks at the proper level for the constantly increasing complexity of agricultural technology without increasing the level of automation, introducing modern digital control and monitoring systems, and advanced methods of information support for all operating modes. However, the task of building information and diagnostic systems is not unambiguous in solutions and requires serious justification when choosing strategies for their implementation. [1]

In order to identify the features of solving information and diagnostic tasks based on the use of an expert decision support system (EDSS) as an object of research, we will consider a grain harvester of the "classical" type of the 5th class («RostSelMash»-Don-1500 or Acros). The relevance of the tasks of reducing the time and improving the accuracy of solving diagnostic problems for such combines is determined by their productivity $(q=8 \div 9,5 \mathrm{~kg} / \mathrm{f})$ and cost (about $5 \mathrm{mln}$ rubles). The using of an expert-diagnostic system for making decisions on the state and possibilities of further operation of the combine in the identified conditions is a new task for the control system of this group of combine harvesters. [2, 3]

\footnotetext{
*Corresponding author: vadim.gritsenko75@mail.ru
} 


\section{Content}

Currently, the combine control system (CCM) is usually local and is designed to collect, process and display information on the state of systems, aggregates and units of the combine, tuning parameters, quality indicators of its operation, notification of emergencies and failures through graphic, sound and speech information with fixation of the date and time of their occurrence. Information panel PI-142-03 was applied. CCM is a rather complex system operating in difficult conditions. Its "contribution to the total piggy bank" of combine failures is approximately $(4 \div 6) \%$, which is quite a lot for a system that is not the main functional purpose. [4-6]

The reliability of combine harvesters, like all types of agricultural machinery, is assessed by two indicators:

— operating time for one technical failure $\left(T_{0}, \mathrm{~h}\right)$;

- availability function $\left(K_{g}\right)$.

The first indicator is determined by dependence:

$$
T_{0}=\frac{T_{S}}{m}
$$

and second:

$$
K_{g}=\frac{T_{S}}{T_{S}+t_{p r}}
$$

$T_{S}$ is the operating time of one combine (better - the study group) in one season, $m$ is the number of recorded failures over time $T_{S}, t_{p r}=t+t^{\prime \prime}$ is total time spent on detecting and eliminating all $m$ failures (here $t^{\prime}$ is the time of control and diagnostic operations, $t^{\prime \prime}$ is the time of repair and restoration operations).

Note that these times largely depend on factors related to the quality of the control and diagnostic system $\left(t^{`}\right)$ and many factors, such as labor costs, delivery of spare parts and repair equipment, qualifications of specialists, etc. These times are interconnected through the quality indicators of the monitoring and diagnostic system (for example, the risks of errors).

At the same time, the analysis of the technical level of "RostSelMash" combine harvesters, carried out by the research of the Russian State Agricultural University, Lomakin S.G. and Berdyshev V.E., made it possible to conclude that an increase in reliability indicators above the level justified in the Russian Federation ( $T_{0} \geq 25 \mathrm{~h} ; K_{g}=0,95$ ) causes a significant increase in costs in the production and technical service of combine harvesters without a noticeable effect on their performance. [7, 8]

It is possible to increase the $T_{0}$ and $K_{g}$ indicators if a well-built EDSS system is able to distinguish the so-called partial failures (PF) [9], in which all the functional capabilities of the technical device (in our case, the combine) are not damaged and the possibility of operating as intended until the most convenient conditions for recovery, i.e. elimination of such a failure. Several works have been devoted to the issue of PF and the construction of the corresponding EDSS. [3, 4, 10, 11]

In this case, the EDSS has the following tasks:

1) Determination of the probable current state of the system in conditions of uncertainty. 
2) Updating statistical data in the $\mathrm{DB} / \mathrm{KB}$.

3) Analysis of the capabilities of the technical system functioning in a PF.

4) Determination of the most effective strategy for continuing the operation of the system in the post-failure period.

In this case, the system "man-EDSS-object" is formed, in which the expert system provides the processed data and transmits the answer for consideration for further decisionmaking in the current situation. The final decision is made by a person, both on the basis of the answer of EDSS, and from personal subjective professional experience. [12]

The placement of such systems individually on a separate unit, for example, a combine harvester, is extremely unprofitable, therefore it seems to install equipment for assessing the condition of the units in a separate center, which will lead both to monitoring the condition of individual machines and to assess the situation throughout the area of proposed work. [13, 14]

The main conclusion that can be made is that such a system, in comparison with conventional control systems, is more complex in terms of the amount of information received and transformed, required for conclusions with high reliability (i.e., minimal risks due to erroneous decisions) [15]. Upon further consideration, the question arises of the feasibility of introducing such a diagnostic system into the reliability management loop, in connection with which an analysis of the costs of using the necessary equipment and damage from identified failures is considered.

The calculation of costs for the use of diagnostic devices is carried out by identifying the total time of the system and hourly costs: $[8,16,17]$

$$
\mathrm{Z}_{\mathrm{com}}=\sum_{i=1}^{m} T_{i} z_{i}
$$

$T_{i}$ is the operating time of the diagnostic system (h), $z_{i}$ is the costs for one hour of operation of the diagnostic system ( $\mathrm{rub} / \mathrm{h}), m$ is the number of diagnostics performed.

On fig. 1 shows a block diagram of the interaction of agricultural machines with the diagnostic center. Data exchange, as can be seen from the diagram, is carried out using the Internet, but this is not necessary, since you can use satellite, radio and other types of communication. The telemetry center acts as a connecting link for receiving information from agricultural machines, registering (Registration system) and transmitting further along the structure. Monitoring and diagnostic system (MDS) analyzes the current state of the equipments. EDSS, as mentioned above, performs the functions of an "adviser", which provides the most suitable option for further work, which in turn can be rejected or, conversely, taken by decision-makers (DM).

The algorithm of the decision-making process about the next steps of actions, taking into account the possible identification of an emergency response, may be as shown in fig. 2 . 


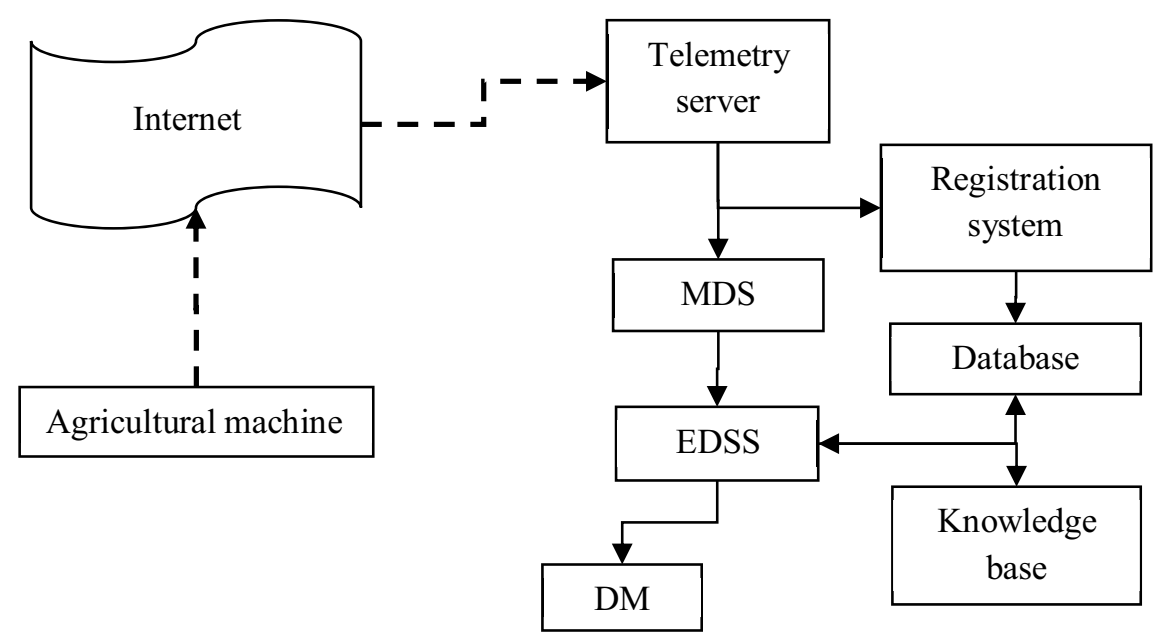

Fig. 1. Diagram interaction of processing diagnostic information.

To assess the possible costs (time and, accordingly, financial) associated with failures during the main operation of the combine harvesters for their intended purpose, we will use the data given by Ph.D. Korolev A.E. in [18]. These statistics are collected based on the results of observations of 10 combine harvesters of the same type under operating conditions during one harvesting season (approximately 250 hours/machine):

— total average number of failures of 1 combine (per season) - 7;

- total relative number of complex failures $-30 \%$;

- total loss of recovery time - 20 hours/comb.

The statistical data were not tied to the operating parameters, which are called "typical". It is highlighted that the largest number of failures relates to headers. The second place is taken by the threshing and separating devices, the third is the electrical equipment.

It can be seen from the above data that only because of the temporary losses associated with the restoration of operability, the results of the work of about one out of ten highperformance combines are lost in overall productivity.

However, the averaged data practically do not reflect the dynamics of changes in the performance indicators in time of the general use of expensive combines in terms of service life over the entire life cycle. The co-owner of "RostSelMash" K. Babkin defines the "normal" service life of a combine harvester at 10 years, but does not exclude that in many cases it can increase several times. Naturally, in such a time frame, the "exhibition polish" of combines will go away, and the statistical data on reliability will not change for the better. First of all, this refers to the failure rate and mean time between failures. It is expected that the processes of diagnostic assessments and decision-making about actions after the manifestation and detection of failures will become more complex.

Currently, according to data from Pavel Kosov, General Director of «RosAgroLeasing», the fleet of grain harvesters in the Russian Federation is approximately 121,000 units. Moreover, $44 \%$ of them are already over 10 years old, i.e. are in a rather worn-out condition, but at the same time they can perform the functions assigned to them. The total share of domestic equipment by the end of 2021 should be about 59\%. During the year, the market volume of domestic harvesters such as ACROS 142, 152 "RostSelMash " is planned to increase by $20 \%$. This means that the issues of technical support of imported agricultural machinery by foreign manufacturers will weaken, which means that the regulatory restrictions imposed by the obligations to comply with the operational standards stipulated 


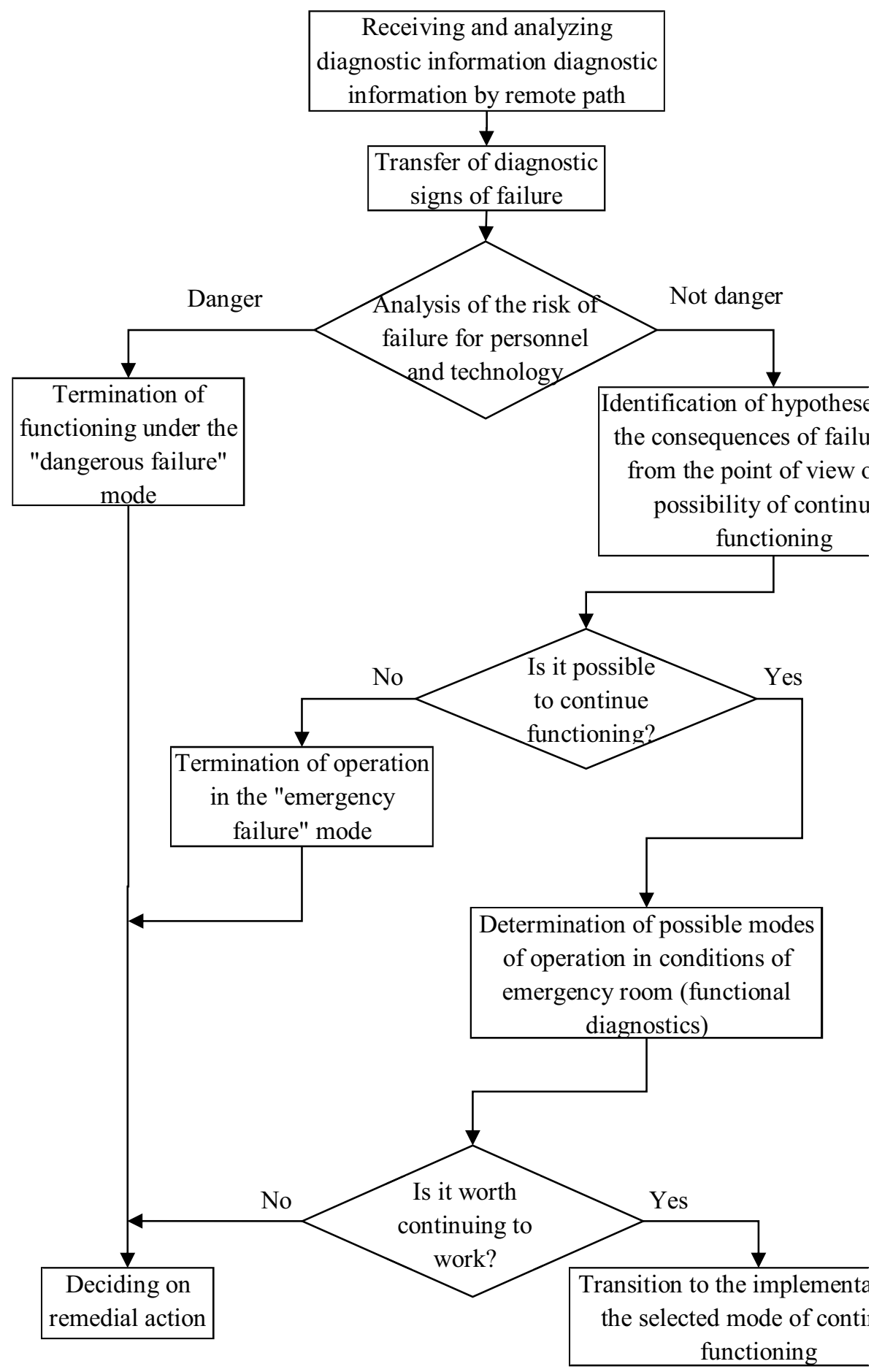

Fig. 2. Algorithm for the implementation of decision-making processes taking into account the possible PF. 
in contracts with suppliers will also weaken. In relatively small farms, control, diagnostic and, possibly, recovery procedures with worn out complex and expensive agricultural equipment will be solved without proper scientific and technical justification. [16] Past experience shows that this approach complicates organizational approaches and increases costs.

Based on the foregoing, the relevance of the formulation of tasks for identifying ER and making informed decisions that reduce losses due to the rational use of permissible recovery strategies is increasing. The task of centralizing the system of assistance with expert assessments in situations requiring decision-making after the manifestation of partial failures may also become relevant.

The strategy of actions in the event of failures can be as follows: control - diagnostics (identification of the place, type and cause of failure) - expert assessment of the result determination of the possibility of continuing work or transition to a new permissible mode of operation - decision making. In some cases, the system can offer several options for making a decision with a risk assessment for each of them. The construction of such a system will require the development of appropriate algorithms and the creation of the necessary information system.

Since in the price-quality ratio, known for any equipment, the priority is increasingly given to price (and the price of domestic and especially imported harvesters is growing rapidly), it is necessary to look for a compromise when solving the contradictory problem that has arisen [21]. It can be resolved when creating a hierarchical EDSS, built on the principle of a single analytical center for certain types of complex agricultural machinery, with a subsequent increase in the level of centralization and expanding the range of tasks to be solved. Proposals for this approach have already been made at the «InterAgroMash-2020» forum. [9] In addition, there are already developments of systems that solve similar problems, which allows us to consider them as basic and use the developments made. This makes it possible to reduce the range of tasks to be solved by paying more attention to the principles implemented in the EDSS and the quality of the corresponding software. The system of remote access for monitoring the technical condition of the MTP in the agro-industrial complex, developed at the Federal State Budgetary Scientific Institution GOSNITI, can be considered as the basic one. This system is based on: a hardware and software complex with the industry application "Agroprom" and the equipment of the company "Global Automation Systems "GLOSAV". The system «Remote Diagnostics» will allow service centers and emergency support to perform diagnostics remotely, which will reduce the time, it takes to obtain the necessary data. Note that such an approach will not lead to a significant complication of the on-board digital systems of combines (and hence an increase in their cost and a decrease in reliability), and the costs for the operation of a centralized EDSS distributed over many farms will also not be very significant.

\section{Conclusions}

1. The increasing complexity of the agro-industrial complex equipment and, in particular, combines exacerbates the issues related to ensuring the required level of reliability in terms of solving control and diagnostic tasks.

2. A decrease in the quality of control and diagnostics leads to production losses, while an increase leads to an increase in the cost of equipment, which upsets the balance in the "pricequality" system.

3. An increase in the reliability indicators of combines can be achieved by using an expert decision support system - EDSS in diagnostic procedures in order to identify partial failures, allowing to increase the time of effective work and reduce the recovery time. 
4. To build a centralized EDSS, you can use the existing remote access systems for monitoring the technical condition of MTP in the agro-industrial complex.

\section{References}

1. Implementation of innovative technical service technologies. FSBSI «Rosinformagrotech», 164 (2014)

2. Comparative tests of agricultural machinery. FSBSI «Rosinformagrotech», 416 (2014)

3. A. Antonov, V. Chepurko, Mathematical model for calculating reliability characteristics NPP equipment under honhomogeneous flows failure. Reliability: Theory \& Applications, 38-56 (2017)

4. B. Sania, R. I. Gatawab, I. Yusufc, Reliability assessment of deteriorating system, Reliability: Theory \& Applications 20-28 (2017)

5. I. B. Shubinsky, Dr. Hendrik Schäbe. On the definition of functional reliability. Reliability: Theory \& Applications, 8-18 (2012)

6. K. Kolowrocki, J. Soszynska-Budny, Reliability optomization of complex systems. Reliability: Theory \& Applications 94-106 (2013)

7. C.G. Lomakin, V.E. Berdnikov, Analysis of the technical level harvesters of «Rostselmash», «Technique and technologies of agro-industrial complex» 6, 34-41 (2017)

8. 1. V. Borisova, I. N. Nurutdinova, V. P. Dimitrov. Approach to the problem of choice of the adjustable harvester parameter values based on fuzzy modeling. Vestnik of don state technical university 2(81), 100-107 (2015)

9. A. Zotov, V. Gritsenko, A. Gazizov, About some possibilities of diagnosing partial failures arising in complex agricultural machinery. E3S Web of Conferences 175 (2020)

10. V.V. Gritsenko, A.I. Zotov, Reliable model of partial failure in a technical system. Engineer's vestnik of Don 2 (2019)

11. B. Tchórzewska-Cieślak, Fuzzy failure risk analysis in drinking water technical system. Reliability: Theory \& Applications 138-148 (2011)

12. N.A. Banushkina, A development technique for expert systems of road safety management in settlements. News of Altai State University (2015)

13. M.A. Pletnev, N.V. Volkov, Expert system "diagnostic and fault removal in cars". Information innovative technologies 1, 516-519 (2017)

14. A.S. Khismatullin, E.V. Sirotina, R.R. Bakirov, Sh.D. Karimov, Diagnostic system to monitor the transformer with the automated control system. Components of scientific and technological progress 9(51), 10-13 (2020)

15. A.V. Matokhina, A.A. Kizim, Describing technical system monitoring, diagnostic and modernization methodology. Information innovative technologies 1, 455-458 (2017)

16. A. V. Antsupov, A. V. Antsupov, V. P. Antsupov, Designed assessment of machine element reliability due to efficiency criteria. Vestnik of nosov magnitogorsk state technical university 5(45), 62-66 (2013)

17. G. Kharmanda, I. Antypas. Integration of Reliability Concept into Soil Tillage Machine Design. Vestnik of don state technical university 2(81), 22-31 (2015)

18. A.E. Korolev, Combine system failures. «The age of Science» 18, 201 (2015)

19. V.V. Gritsenko, A.I. Zotov, Degradation model of partial failure in a technical system. Engineer's vestnik of Don, 1 (2019) 
20. V.V. Gritsenko, A.I. Zotov, On the question of parametric models of partial failures in technical devices. Engineer's vestnik of Don 4 (2019)

21. O. Serdiuk, Formation of a conceptual approach to the creation of an expert system for the identification of the processes of intellectual activity. Eastern-European Journal of Enterprise Technologies 2(78), 11 (2015) 